\title{
An Examination of Communication Skills Curricula across Two European Medical Universities
}

\author{
Tamara Seitz, Bela R. Turk, Charles Seidman and Henriette Löffler-Stastka* \\ Medical University of Vienna, Vienna, Austria
}

The advancement of communication skills and bedside manner training for medical students is crucial to modern medical curricula. In this study, we compared the curricula of two central European universities, the Medical University of Vienna and the Medical University of Basel. A systematic search of literature was performed identifying nine publications. These sources were used to identify major differences between the curricula. One setting integrates clinical specialty content from seven different specialties into communication training in theory and simulated-based training. The other provides specialized training for psychiatric patients only, strengthening reflective

OPEN ACCESS

Edited by:

Rukhsana Ahmed,

University of Ottawa, Canada

Reviewed by:

Carmel Maree Loughland,

University of Newcastle, Australia

Victoria Team,

Monash University, Australia

*Correspondence:

Henriette Löffler-Stastka henriette.loeffler-stastka@ meduniwien.ac.at

Specialty section: This article was submitted to Health Communication,

a section of the journal

Frontiers in Communication

Received: 17 June 2016 Accepted: 10 October 2016 Published: 25 October 2016

Citation:

Seitz T, Turk BR, Seidman C and Löffler-Stastka H (2016)

An Examination of

Communication Skills Curricula across Two European Medical Universities.

Front. Commun. 1:11.

doi: 10.3389/fcomm.2016.00011 capacity. The first mentioned site implements more frequent Objective Structured Clinical Examinations. The increased frequencies support cumulative learning strategies in content delivery. Furthermore, it allows for repetition of core content which increases students' knowledge and improves their skills'. Elucidating these and other differences and similarities may facilitate targeted improvement of the current communication skills training framework.

Keywords: communication skills, health knowledge, attitudes, practice, bedside manner, educational status, education, medical, participatory sense-making

\section{INTRODUCTION}

Adequate communication skills allow an engaged doctor-patient communication and build a patient-professional relationship. Obtaining good communication skills are crucial for every physician concerning diagnostic and clinical reasoning processes. For example, during the first doctor-patient talk up to $76 \%$ of diagnosis has been shown to be made correctly if the doctor's communicative skills are sufficient (Peterson et al., 1992). Patients' satisfaction with physician's ability to communicate effectively has the potential to increase their adherence to therapy and keeping appointments, to improve transfer of critical medical information, and to improve their health outcomes (Schmid Mast et al., 2004). Furthermore, physicians' levels of empathy positively correlate with the patients' levels of satisfaction (Schmid Mast et al., 2004; Derksen et al., 2013). Empathy lowers patients' anxiety, strengthens patients' enablement and distress, and delivers significantly better clinical outcomes (Derksen et al., 2013). For example, the majority of patients not only in the United States of America (Mazor et al., 2005; Verghese et al., 2011) but also in Switzerland (Langewitz et al., 2002) and Austria (Sator et al., 2008) were shown to be unsatisfied with the quality of the doctor-patient communication. One of the reasons is the lack of adequate patient-centered communication, leading to patients' dissatisfaction and to increased frequency of physician errors (Chen et al., 2008). The discussed issues are reported as possible reasons for the increasing number of medical malpractice cases (Wienke, 2013) and court cases (Tamblyn et al., 
2007) in Germany and Canada. There are no data about this topic in Austria or Switzerland. At last, physicians have to adapt their communication skills to the challenging changes for the future population in Austria. Aging and migrating demographic populations may make doctor-patient communication more difficult. For example, due to a higher prevalence and frequency of patients with speech impairment, such as dementia or stroke, and increasing language barriers (Statistik Austria, 2011, 2013), communication becomes more complex and difficult, if physicians are not prepared for these changes.

Therefore, the continued development of communication skills and bedside manner training for medical students is crucial for medical universities. Historically, communication skills' training was not part of the medical education curricula in most parts of the globe until more recent years (Kurtz et al., 1999). Communication skills can be taught by qualified teachers as part of a structured training curriculum (Kurtz et al., 2009). When students learned communication skills autonomously during clinical training, competency development was less effective (Langewitz et al., 1998). Therefore, expert consensus in Canada, United States of America, and Switzerland currently advocates communication training as a core element of medical education (Makoul, 2001; Kiessling et al., 2008).

The Medical University of Vienna (MUV) saw widespread curricular restructuring in the early 2000s and adopted the curriculum of the Medical University of Basel (MUB) (Kiessling et al., 2008), a model that had been previously implemented at the University of Basel with success. The MUB model featured the training of communication skills and bedside manner as a core curricular element. Following positive student and educator reception, an ensuing guideline was published in the Basel Consensus statement. However, medical licensing requirements differ between Austria and Switzerland, the former not requiring medical students to pass national licensing examinations. Instead, Austrian medical universities themselves are relied upon the implementation of the curricular goals and evaluate the results (Merl et al., 2000).

Over a decade has passed since the previous MUV (Merl et al., 2000) curriculum reform and a review of communication and bedside manner training at both the MUV and the MUB universities may facilitate its development. In this study, the deputy dean and the members of the curriculum planning committee together with the final grade students at the MUV assessed and compared differences in curricular content, structure, didactic method, and examination method relating to communication and bedside manner between the MUB and MUV. It is important to note that the differing methods of teaching communication and empathy are not unique to these two universities. The curriculum of the MUB has been widely adopted across other medical universities in Switzerland and Germany (including the University of Heidelberg), while the MUV curriculum has been adopted across Austria (Bloch and Burgi, 2002; Medical University of Vienna, 2014). Thus, the findings of this particular study could be of interest to curriculum developers in other universities. We anticipate that the results of this study will establish a basis for further evaluation studies focused on communication skills of medical students.

\section{METHOD}

A systematic search of literature was performed for publications relating to communication skills and bedside manner training at the MUB and MUV. The aim is to improve deficits there as recommended by the curricular advisory board. Literature search was performed using the National Institute of Health U.S. National Library of Medicine search directory for MEDLINE and SCOPUS between July and August 2014. Keywords included "Medical University of Basel," "Medical Faculty of the University of Basel," "Medial University of Vienna," "Medizinische Universität Wien," "Medizinische Universität Basel," "Medizinische Fakultät der Universität Basel" AND "communicative skills," "communication," "communicative training," "anamnesis," "doctor-patient communication," "doctor-patient talk," "empathy" dating from 1995 to the present date. We further assessed the abstracts and excluded all papers that did not relate to communication skills training at both universities. Another criterion for exclusion was limited access to the full version. The websites of both universities were indexed and searched using Google algorithms for current curricular structure. All authors participated in the assessment of indexed citations and developed a list of comparison categories for further analysis. For curricular content comparison, we analyzed competence catalogs at both universities (Bloch and Burgi, 2002; Medical University of Vienna, 2014). They include a list of the main skills that medical students should attain during the course. As suggested by the curricular advisory board at the MUV, curricular comparison was separated into the following nine different assessment categories:

(1) Curricular structure: this category includes a short summary of the number of hours spent for communication and bedside manner training at MUV and MUB, as well as in which respective academic year the training was provided. Additionally, the teaching method, the class size, the use of technology in class, and the following tests, examination and assessment methods were evaluated.

(2) Qualification profile: both universities have a published qualification profile, outlining which skills their medical graduates will be proficient in. The MUBs Swiss Catalogue of Learning Objectives (SCLO) serves as an outline for the Swiss Federal Licensing Examination (SFLE) (Bloch and Burgi, 2002). The MUV employs the newly implemented Austrian Competence Catalogue for Medical Skills (ACCMS) (Österreichischer Kompetenzenkatalog für Ärztliche Fertigkeiten, ÖKÄF) (Merl et al., 2000).

(3) Time allotment for student learning: the time allotment is counted in academic classes (AC) (Unterrichtseinheit). An AC comprises $45 \mathrm{~min}$ of instruction.

(4) Individual class content and materials (e.g., text book, communication protocol).

(5) Class size (L, small group, numerical teacher-students relation).

(6) Training and evaluation of teaching personnel (e.g., compulsory faculty training seminars, hospitations/job shadowing, peer-group evaluation). 
(7) Use of technology and didactic methods in classes: modalities were categorized as one of the following: on campus lectures or face-to-face instructions with little to no interactivity designed for large groups of students (L). Group seminar, a small group with a maximum size of 20 students designed for high interactive learning (GS), simulated patient training involved either acting patients, colleagues, or educators posing as patients, or simulated patient environments such as interactive electronic dummies (SP).

(8) Class attendance requirements (compulsory entrance tests, successful completion of prior courses/curriculum elements, e-learning, or video-training).

(9) Examination and testing methods (formative or summative tests, structured skills examinations, and clinical evaluation exercises).

\section{RESULTS}

\section{Literature Search}

Two hundred twelve citations were initially included. After exclusion criteria were applied, five WebPages and four publications were included. They are listed in Table 1.

\section{Curricular Structure}

A comparison of the curricula of MUB and MUB is summarized in Table 2. According to the MUB curriculum, on campus lectures (L) are the main teaching mode in introductory courses, followed by small group seminars (GS). Course content and application of knowledge is tested using Objective Structured

TABLE 1 | List of sources selected for analysis.

\begin{tabular}{l} 
WebPages \\
\hline 1. Medical University of Vienna. Data from: Österreichische \\
Kompetenzkatalog für ärztliche Fertigkeiten \\
(2014). http://kpj.meduniwien.ac.at/fileadmin/kpj/ \\
oesterreichischer-kompetenzlevelkatalog-fuer-aerztliche- \\
fertigkeiten.pdf \\
2. Universität Basel der MF. Data from: Konzept der \\
Lehr-Evaluation an der Medizinischen Fakultät zu Basel \\
(2009). http://medizinstudium.unibas.ch/allgemeine- \\
infos/evaluation-der-lehre.html \\
3. Medical University of Vienna. Data from: Österreichische \\
Kompetenzkatalog für ärztliche Fertigkeiten (2013). \\
https://studyguide.meduniwien.ac.at/curriculum/n202- \\
2013/attachment/3905/download/23_oesterreichischer- \\
kompetenzlevelkatalog-fuer-aerztliche-fertigkeiten.pdf \\
4. Medical University of Vienna. Data from: 14 . \\
Mitteilungsblatt. Nr.17. 2011. Medizinische Universität \\
Wien (2014). http://www.meduniwien.ac.at/homepage/ \\
fileadmin/HP-Relaunch/pdfstudien/HumanmedizinN202/ \\
Curriculum_Humanmedizin2012.pdf \\
5. Medical University of Vienna. Data from: Ärztliche \\
Gesprächsführung lehren: Der Einsatz von \\
Schauspielpatienten an der MedUniWien (2014). \\
http://www.gutelehre.at/lehre-detail/?tx_bmwfwlehre_ \\
pi1\%5Bproject\%5D=394\&tx_bmwfwlehre_ \\
pi1\%5Bcontroller\%5D=Project\&tx_bmwfwlehre_- \\
pi1\%5Baction\%5D=detail\&cHash=e7403dd472 \\
cebc791b5eaf91399aea7f
\end{tabular}

Video Examinations (OSVE) or Objective Structured Clinical Examination (OSCE). OSVE testing requires students to give feedback on and analyze methods used by certified doctors in practice in pre-recorded videos. The OSCE is a simulated patient examination scenario, where students perform short clinical tasks and are evaluated on their performance, including their bedside manners. Theoretical knowledge is also tested using multiple choice questionnaires (MCQ).

All students are required to spend 4 weeks as nursing-interns prior to their medical curriculum. During the first year, $\mathrm{L}$ and role playing GS demonstrate expected standards of bedside manner. Trained tutors, on one hand, provide verbal feedback to students after training, on the other hand, teach students to give feedback adequately by themselves to other students. Furthermore, they teach exercises for dealing with stress occurring from difficult talks with patients.

During the second year, focus is set on communication techniques. Using simulated patient (SP) courses, students practice bedside manner while being video-recorded. Afterward, feedback by colleagues and tutors is given. During the third year, communication techniques and bedside manner are integrated into field-specific activities, including taking of a patient's history, first using role playing GS, then in clinical practice. Certified physicians of each respective field (e.g., internal medicine, general surgery, pediatrics, obstetrics/gynecology, etc.) supervise students and assess their communication skills. At this stage, role playing scenarios are still employed in SP seminars to better simulate challenging patient interactions, especially those who may impact the patient's sense of autonomy.

The focus of the fourth academic year is to deliver bad news by employing role playing GS. Students are coached by both an oncologist and a psychiatrist as mentors. During the final 2 years, Balint (Bloch and Burgi, 2002) group electives are provided. A Balint group is a group of people, mostly physicians who meet regularly and present interesting cases to each other followed by further discussion (Balint, 1957). The aim of the Balint groups is to explore, contain, and transform any uncertainties, conflicts, and potential difficulties in the doctor-patient relationship and improve the therapeutic alliance between clinician and patient (Balint, 1957). Anyway, these groups see little use at MUB.

According to the MUV curriculum, communication, social competence, and bedside manner classes are taught over 4 years of preclinical and clinical study. Two examinations take place at the end of the second and fourth year in the form of an OSCE, testing bedside manner in situations with SP contact. Theoretical knowledge is tested using MCQs at the end of the first year and is known as Summative Integrative Prüfung (SIP).

During the first year, students are introduced to the social competencies expected of a practicing physician. A short GS introductory course details basic communication paradigms before students must complete a communication course in a geriatric assisted living facility. Students are required to communicate with elderly patients and assist them in some of their daily tasks. This course if followed by a GS in which students reflect up on experiences and challenges in communication.

During the second year, students in GS use role-play situations to practice taking a patient's medical history with an emphasis on 
TABLE 2 | A comparison of communication skills training between the MUB and MUV.

\begin{tabular}{|c|c|c|c|c|c|c|c|c|}
\hline & \multicolumn{2}{|c|}{ Learning modality and total time } & \multicolumn{2}{|c|}{ Relation teacher to students } & \multicolumn{2}{|c|}{ Compulsory attendance } & \multicolumn{2}{|c|}{ Test } \\
\hline & MUB & MUV & MUB & MUV & MUB & MUV & MUB & MUV \\
\hline \multicolumn{9}{|l|}{ AY 1} \\
\hline & $\mathrm{L}(7 \mathrm{AC})$ & $L(5 \mathrm{AC})$ & 1:all & 1:all & No & No & None & SIP \\
\hline & GS (6 AC) & GS (10 AC) & $1: 10$ & $1: 10$ & No & Yes & MCQ & None \\
\hline & $x$ & $\mathrm{PR}(10 \mathrm{AC})$ & & & & Yes & & None \\
\hline \multicolumn{9}{|l|}{ AY 2} \\
\hline & $\mathrm{L}(6 \mathrm{AC})$ & $L(2 \mathrm{AC})$ & 1: all & 1:all & No & No & OSVE & KOS-test \\
\hline & $x$ & GS (12 AC) & & $1: 10$ & & Yes & & FAMPROP \\
\hline & $\mathrm{SP}(5 \mathrm{AC})$ & x & $1: 4$ & & No & & OSVE & \\
\hline \multicolumn{9}{|l|}{ AY 3} \\
\hline & $L(11 A C)$ & $x$ & 1: all & & Yes & & OSCE & \\
\hline & GS (14 AC) & $x$ & $1: 12$ & & No & & OSCE & \\
\hline & $\mathrm{SP}(14 \mathrm{AC})$ & $\mathrm{SP}(15 \mathrm{AC})$ & $1: 8$ & $1: 10$ & Yes & Yes & OSCE & OSCE \\
\hline \multicolumn{9}{|l|}{ AY 4} \\
\hline & $L(1 \mathrm{AC})$ & $\mathrm{L}(4 \mathrm{AC})$ & 1:all & 1:all & No & No & OSCE & OSCE \\
\hline & GS (3 AC) & $\mathrm{SP}$ (12 AC) & $2: 16$ & $1: 10$ & No & Yes & OSCE & OSCE \\
\hline & $X$ & IS & & & Yes & Yes & OSCE & OSCE \\
\hline
\end{tabular}

AY, academic year; $A C$, academic class (a 45-min).

professionalism and empathy. Tutors and several physicians serve as mentors. An MCQ, the knowledge on skills test (KOS-test), is utilized to evaluate the theoretical knowledge. A kind of OSCE (FAMPROP) evaluates the practical communicative skills at the end of the course, a requirement in passing the year. Positive KOStest and OSCE scores are considered as the eligibility criteria for applying for clinical studentships, as the MUV will only recognize mandatory studentships performed after successful completion of the second year of study.

During the third year, GS with SP training allow emotionally challenging topics to be introduced into communication and social competency training, for example, delivering bad news to patients with hearing problems. The student-patient conversation is video-recorded and then evaluated by the fellow students and a physician.

During the fourth year, the communication training focuses on challenges in communication with the mentally ill patients admitted in psychiatric facilities. L and textbooks provide the required background information on communication challenges. A mandatory e-learning program aims to make the communication knowledge and management paradigms applicable in a clinical setting. Following the e-learning program, small GS with SP contact require students learn to assess mental states and to communicate with patients with depressive and suicidal tendencies, alcoholism, anxiety disorders, and chronic pain. Certified psychiatrists serve as mentors and provide a feedback in these GS. At the end of the fourth year, an OSCE evaluates communicative and social competencies in these aforementioned scenarios.

Students in their final sixth year, starting from 2014, do not receive L or GS in any medical field; instead, they are required to seek and gain employment as medical student interns at teaching hospitals either nationally or internationally via studentships. Successful completion and evaluation during this clinical practical year (Klinisch Praktisches Jahr, KPJ) is required for graduation from the university.

\section{Qualification Profile}

The Swiss qualification catalog is less rigid than the Austrian one, allowing the university more freedom in curricula: in The Swiss SCLO does not contain a temporal structure; students are required only to attain all the skills until graduation, allowing Swiss medical universities freedom in curricular structuring. The Austrian ACCMS has three levels of competencies: competencies required for clinical studentship, competencies required for clinical internship, and clinical practical year.

\section{Time Allotment for Student Learning}

The MUV curriculum offers a higher total AC, as the practical course in a geriatric assisted living setting is included and counted as communication training. The MUB curriculum does not include the 4-week mandatory nursing internship. The MUB curriculum has a total of 25 ACs of L, 23 ACs GS, and 19 ACs SP. The MUV has 11 ACs of L, 22 ACs of GS, 27 ACs of SP, and 10 ACs of PR.

\section{Individual Class Content}

Both curricula offer introductory L and GS, basic communication protocol, paradigm training, and an advanced scenario training. However, only MUB includes medical specialty/domain - specific content and the different communication environments. The MUB incorporates this specialized communication training for several medical fields in theory, practice, and SP contact, while the MUV only provides specialized training in communication regarding psychic complaints of patients.

\section{Class Size}

The MUB average class size is with 8.4 (range: 4-12) students smaller than the standardized MUV class size with 10 students.

\section{Training and Evaluation of Teaching Personnel}

Both the MUB and the MUV require "sufficient training" of medical educators. Specific training requirements are less transparent, 
and the authors were unable to find requirements for the MUB. The MUV requires eight $\mathrm{AC}$ of didactic seminars and six $\mathrm{AC}$ of teaching assistance for eligibility in teaching a specific class.

\section{Use of Technology and Didactic Methods in Classes}

Both the MUB and the MUV employ similar didactic methods and technologies in classes: GS at both universities employ role playing, SP contact, and video-recording with feedback and analysis by educators and peers. The MUB framework additionally requires and examines students on communication paradigms in practice with real patients as opposed to the MUVs SP examination setting. The MUV requires students to complete a mandatory, case-based, question-driven e-learning program in preparation for SP contact (Turk et al., 2015). It also requires reflective writing on participant observation and active performance in history taking and exploration seminars in the third and fourth academic year.

\section{Class Attendance Requirements}

The class attendance is at MUB much less rigid than at MUV: the MUB has no attendance requirements, except for classes during the third year of medical school, in which L, GS, and SP require compulsory attendance. The MUV has a $100 \%$ attendance requirement for GS and practical courses, but not for $\mathrm{L}$.

\section{Examination and Testing Methods}

Students' social and bedside communication skills are evaluated more often and regularly at MUB than at MUV. At MUB, evaluations of students' skills are carried out every half year with SP contact via OSCE and OSVE. Knowledge of communication skills is tested in yearly MCQs. At MUV, two examinations asses the application of communication skills, one during the second year and one at the end of the fourth year. Both OSCE examinations involve SP contact. Reflective writing is assessed via portfolios.

\section{DISCUSSION}

The Austrian ACCMS catalog defines a timeframe (year 2, year 5 , and graduation), by which students' communication skills should be developed. While this aims to standardize skill levels on a national level, the MUV curriculum is bound to these goals allowing developments or restructuring only within the year of study. Changes to the current curriculum are implemented separately for each year group, and aim to optimize student knowledge and skill base at studentship and internship level, years 3 and 6, respectively. For example, should the third year medical student be fully trained in promoting patient autonomy in a direct conflict situation with a grieving family or is it better to focus on acquiring and utilizing a high standard of medical history taking skills? The authors support the necessity of these discussions with respect to the time and financial constraints imposed by a 5-year medical curriculum. Nevertheless, implementation of future developments of communication and bedside manner profile requirements in MUV could be refined especially concerning the vertical attunement (years 1-6) and the horizontal content-skills matching. On the other hand, specific communication skills training could be included in postgraduate courses and combined with concise bedside manner competency training. Based on the curricular model of the University of Basel, we suggest to reduce the average class size in the University of Vienna, because small class sizes have shown greater effectiveness in medical education, allowing more practice time per student and more individualized feedback (Aspegren, 1999; Bloom, 2005).

The strategy of content delivery in Basel University, both of L and GS, is cumulative in nature, each class basing its content on previous courses while repeating core content. Furthermore, the MUB's approach to attendance requirements is a stark contrast to the MUV's $100 \%$ GS attendance requirements. Examinations every half year may motivate Swiss students to attend classes and become a more intrinsically motivating (Taylor and Hamdy, 2013) approach than the current approach, requiring mandatory attendance and examinations once per year. According to motivational learning theories (Taylor and Hamdy, 2013), we propose that a higher frequency of examinations (multiple OSCEs per year) should be adopted by MUV. Reduced total sum of knowledge that a student is required to learn per exam may facilitate learning process. Furthermore, this approach allows a more cumulative teaching of curricular content with repetitive elements of core knowledge. This maylead, following instrumental learning theories (Taylor and Hamdy, 2013), to a switch from cognitive learning to transformative learning. Besides cumulative, learning has shown a higher effect in student learning, resulting in higher OSCE scores than a single, concentrated course (Van Dalen et al., 2002).

In a recently performed study (Seitz et al., 2015), the researchers interviewed Viennese physician educators who supervised medical students during their studentship. The majority claimed that the MUV students were unable to take a structural and complete medical history due to a lack of practical medical specialty specific knowledge. Thus, MUV may benefit from the integration of medical specialty specific patient history taking and communication frameworks as implemented in MUB, which may be assessed by the fourth year OSCE. The implemented frameworks would improve the MUV students' history taking skills and strengthen their communication practices through patient management in SP or GS settings. This approach may attenuate interdisciplinary learning processes, highlighting vital elements of communication in each field through training rather than through clinical exposure.

\section{SUGGESTIONS FOR FUTURE RESEARCH}

The results of this study establish a basis for further research. Future research projects might evaluate whether the curricular differences led to a better competency in communicative skills (e.g., history taking, diagnostic and clinical reasoning processes, diagnostic precision, and treatment compliance). Competencies of medical students at MUV, MUB, and other universities with similar curricula could be compared. Therefore, surveys on students' and recently graduated physicians' ability to communicate could be performed. Other studies, reflecting students', the supervising physicians', and the patients' perspectives on patientprofessional communication, could be conducted. Further research concerning didactic considerations would be helpful. The researchers may compare different SP-training methods or 
the efficacy of diversification of training methods, for example, case-based learning vs. case-based blended learning with e-learning elements. The potential changes in medical curricula related to communication training may include the implementation of cumulative content delivery, a higher frequency of examinations with reduced content, the integration of specialty skills across multiple clinical domains, a less rigid compulsory attendance requirements, and a smaller class size.

\section{AUTHOR CONTRIBUTIONS}

HL-S designed the investigation, authored and reviewed the manuscript several times, and initiated the international

\section{REFERENCES}

Aspegren, K. (1999). BEME Guide No. 2: teaching and learning communication skills in medicine-a review with quality grading of articles. Med. Teach. 21, 563-570. doi:10.1080/01421599978979

Balint, M. (1957). The Doctor, His Patient and the Illness. London: Tavistock Publications.

Bloch, R., and Burgi, H. (2002). The Swiss catalogue of learning objectives. Med. Teach. 24, 144-150. doi:10.1080/01421590220120759

Bloom, B. S. (2005). Effects of continuing medical education on improving physician clinical care and patient health: a review of systematic reviews. Int. J. Technol. Assess. Health Care 21, 380-385. doi:10.1017/S026646230505049X

Chen, R. C., Clark, J. A., Manola, J., and Talcott, J. A. (2008). Treatment "mismatch" in early prostate cancer: do treatment choices take patient quality of life into account? Cancer 112, 61-68. doi:10.1002/cncr.23138

Derksen, F., Bensing, J., and Lagro-Janssen, A. (2013). Effectiveness of empathy in general practice: a systematic review. Br. J. Gen. Pract. 63, 76-84. doi:10.3399/ bjgp13X660814

Kiessling, C., Dieterich, A., Fabry, G., et al. (2008). Data from: Basler Consensus Statement Kommunikative und soziale Kompetenzen im Medizinstudium: Ein Positionspapier des GMA-Ausschusses Kommunikative und soziale Kompetenzen. [Basel Consensus Statement "Communicative and Social Competencies in Medical Education": A Position Paper of the GMA Committee Communicative and Social Competencies]. Available at: http://www.egms.de/en/journals/zma/2008-25/ zma000567.shtml

Kiessling, C., Fabry, G., Rudolf Fischer, M., Steiner, C., and Langewitz, W. A. (2014). [German translation and construct validation of the Patient-ProviderOrientation Scale (PPOS-D12)]. Psychother. Psychosom. Med. Psychol. 64, 122-127. doi:10.1055/s-0033-1341455

Kiessling, C., and Langewitz, W. (2013). The longitudinal curriculum "social and communicative competencies" within Bologna-reformed undergraduate medical education in Basel. GMS Z. Med. Ausbild. 30, 31. doi:10.3205/zma000874

Kurtz S., Silverman, J., Draper, J. (2009). Teaching and Learning Communication Skills in Medicine. UK: Radcliffe Medical Press.

Kurtz, S. M., Laidlaw, T., Makoul, G., and Schnabl, G. (1999). Medical education initiatives in communication skills. Cancer Prev. Control 3, 37-45.

Langewitz, W., Conen, D., Nübling, M., Weber, H. (2002). [Communication matters - deficits in hospital care from the patients' perspective]. Psychother. Psychosom. Med. Psychol. 52, 348-354. doi:10.1055/s-2002-33079

Langewitz, W. A., Eich, P., Kiss, A., Wossmer, B. (1998). Improving communication skills - a randomized controlled behaviorally oriented intervention study for residents in internal medicine. Psychosom. Med. 60, 268-276. doi:10.1097/00006842-199805000-00009

Makoul, G. (2001). Essential elements of communication in medical encounters: the Kalamazoo consensus statement. Acad. Med. 76, 390-393. doi:10.1097/00001888-200104000-00021 cooperation and comparison. TS compared the curricula, drafted the manuscript, and contacted the international partners on the students' level. BT drafted the manuscript and conducted the literature review. CS strengthened the English language and reviewed the manuscript.

\section{ACKNOWLEDGMENTS}

We thank all members of the curriculum planning committee and medical students of the Medical University of Vienna who contributed a lot to this project, especially we want to thank Ms. Birgit Ludwig, Ms. Isabella Divisch, and Ms. Sarah Knaus. Funding: AP14077BGM.

Mazor, K. M., Ockene, J. K., Rogers, H. J., Carlin, M. M., Quirk, M. E. (2005). The relationship between checklist scores on a communication OSCE and analogue patients' perceptions of communication. Adv. Health Sci. Educ. Theory Pract. 10, 37-51. doi:10.1007/s10459-004-1790-2

Medical University of Vienna. (2014). Data from: Österreichische Kompetenzkatalog für ärztliche Fertigkeiten. Available at: http://kpj.meduniwien.ac.at/ fileadmin/kpj/oesterreichischer-kompetenzlevelkatalog-fuer-aerztlichefertigkeiten.pdf

Merl, P. A., Csanyi, G. S., Petta, P., Lischka, M., and März, R. (2000). The process of defining a profile of student competencies at the University of Vienna Medical School. Med. Educ. 34, 216-221. doi:10.1046/j.1365-2923.2000. 00509.x

Peterson, M. C., Holbrook, J. H., Von Hales, D., Smith, N. L., and Staker, L. V. (1992). Contributions of the history, physical examination, and laboratory investigation in making medical diagnoses. West. J. Med. 156, 163-165.

Sator, M., Gstettner, A., and Hladschik-Kermer, B. (2008). [Doctor-patientcommunication in an oncological outpatient department. A linguistic study of communication problems]. Wien. Klin. Wochenschr. 120, 158-170. doi:10.1007/ s00508-008-0948-y

Schmid Mast, M., Kindlimann, A., and Hornung, R. (2004). How gender and communication style of physicians affect patient satisfaction: the little difference. Praxis 93, 1183-1188. doi:10.1024/0369-8394.93.29.1183

Seitz, T., Turk, B. R., and Löffler-Stastka, H. (2015). They've talked the talk, but can they walk the walk? Physician-educator evaluation of medical students' communication skills in clinical practice - a pilot study. Social Sciences and Teaching Research. Adv. Soc. Behav. Sci. 14, 40-47.

Statistik Austria. (2011). Bevölkerungsvorausschätzung 2011-2050. Available at: http://www.statistik.at/web_de/statistiken/menschen_und_gesellschaft/ bevoelkerung/demographische_prognosen/bevoelkerungsprognosen/index. html

Statistik Austria. (2013). Census 2011 Wien. Ergebnisse zur Bevölkerung aus der Registerzählung. Available at: http://www.statistik.at/web_de/statistiken/ menschen_und_gesellschaft/bevoelkerung/volkszaehlungen_registerzaehlungen_abgestimmte_erwerbsstatistik/index.html

Tamblyn, R., Abrahamowicz, M., Dauphinee, D., Wenghofer, E., Jacques, A., Klass, D., et al. (2007). Physician scores on a national clinical skills examination as predictors of complaints to medical regulatory authorities. JAMA 298, 993-1001. doi:10.1001/jama.298.9.993

Taylor, D. C. M., and Hamdy, H. (2013). Adult learning theories: implications for learning and teaching in medical education: AMEE Guide No. 83. Med. Teach. 35, 1561-1572. doi:10.3109/0142159X.2013.828153

Turk, B. R., Krexner, R., Otto, F., Wrba, T., and Löffler-Stastka, H. (2015). Not the ghost in the machine: transforming patient data into e-learning cases within a case-based blended learning framework for medical education. Proc. Soc. Behav. Sci. 186, 713-725. doi:10.1016/j.sbspro.2015. 04.106 
Van Dalen, J., Kerkhofs, E., van Knippenberg-Van Den Berg, B. W., van Den Hout, H. A., Scherpbier, A. J. J. A., and van der Vleuten, C. P. M. (2002). Longitudinal and concentrated communication skills programmes: two Dutch medical schools compared. Adv. Health Sci. Educ. Theory Pract. 7, 29-40. doi:10.102 3/a:1014576900127

Verghese, A., Brady, E., Kapur, C. C., and Horwitz, R. I. (2011). The bedside evaluation: ritual and reason. Ann. Intern. Med. 155, 550-553. doi:10.7326/0003-4819-155-8-201110180-00013

Wienke, A. (2013). Briefing and accusation of medical malpractice - the second victim. Laryngorhinootologie 92, 1-22. doi:10.1055/s-0032-1333252
Conflict of Interest Statement: The authors declare that the research was conducted in the absence of any commercial or financial relationships that could be construed as a potential conflict of interest.

Copyright (C) 2016 Seitz, Turk, Seidman and Löfler-Stastka. This is an open-access article distributed under the terms of the Creative Commons Attribution License (CC $B Y)$. The use, distribution or reproduction in other forums is permitted, provided the original author(s) or licensor are credited and that the original publication in this journal is cited, in accordance with accepted academic practice. No use, distribution or reproduction is permitted which does not comply with these terms. 